\title{
Special Issue of Best Papers from the 11th International Conference on Systematic Approaches to Digital Forensic Engineering (SADFE 2016)
}

Follow this and additional works at: https://commons.erau.edu/jdfsl

Part of the Computer Engineering Commons, Computer Law Commons, Electrical and Computer Engineering Commons, Forensic Science and Technology Commons, and the Information Security Commons

\section{Recommended Citation}

(2017) "Special Issue of Best Papers from the 11th International Conference on Systematic Approaches to Digital Forensic Engineering (SADFE 2016)," Journal of Digital Forensics, Security and Law. Vol. 12 : No. 1 , Article 4.

DOI: https://doi.org/10.15394/jdfsl.2017.1443

Available at: https://commons.erau.edu/jdfsl/vol12/iss1/4

This Front Matter/Back Matter is brought to you for free

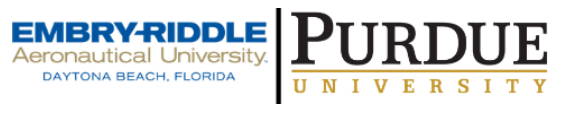
and open access by the Journals at Scholarly Commons. It has been accepted for inclusion in Journal of Digital Forensics, Security and Law by an authorized administrator of Scholarly Commons. For more information, please contact commons@erau.edu.

(c)ADFSL 


\section{Special Issue of Best Papers from the 11th International Conference on Systematic Approaches to Digital Forensic Engineering (SADFE 2016)}

The SADFE series feature the different editions of the International Conference on Systematic Approaches to Digital Forensics Engineering. Now in its eleventh edition, SADFE has established itself as the premier conference for researchers and practitioners working in Systematic Approaches to Digital Forensics Engineering.

SADFE 2016, the eleventh international conference on Systematic Approaches to Digital Forensic Engineering was held in Kyoto, Japan, September 20 - 22, 2016.

Digital forensics engineering and the curation of digital collections in cultural institutions face pressing and overlapping challenges related to provenance, chain of custody, authenticity, integrity, and identity. The generation, analysis and sustainability of digital evidence require innovative methods, systems and practices, grounded in solid research and understanding of user needs. The term digital forensic readiness describes systems that are built to satisfy the needs for secure digital evidence.

SADFE 2016 investigates requirements for digital forensic readiness and methods, technologies, and building blocks for digital forensic engineering. Digital forensic at SADFE focuses on variety of goals, including criminal and corporate investigations, data records produced by calibrated devices, as well as documentation of individual and organizational activities. Another focus is on challenges brought in by globalization and cross-legislation digital applications. We believe digital forensic engineering is vital to security, the administration of justice and the evolution of culture. 
